This journal is the official publication of Bangladesh Society of Physiologists (BSP)

Web URL: www.banglajol.info/index.php/JBSP

Abstracted /indexed in Index Copernicus, Director of Open Access Journal, HINARI Index Medicus for South East Asia Region, Google Scholar, 12OR, infobse index, Open J gate, Cite factor, Scientific indexing services

pISSN-1983-1213; e-ISSN-2219-7508

Article

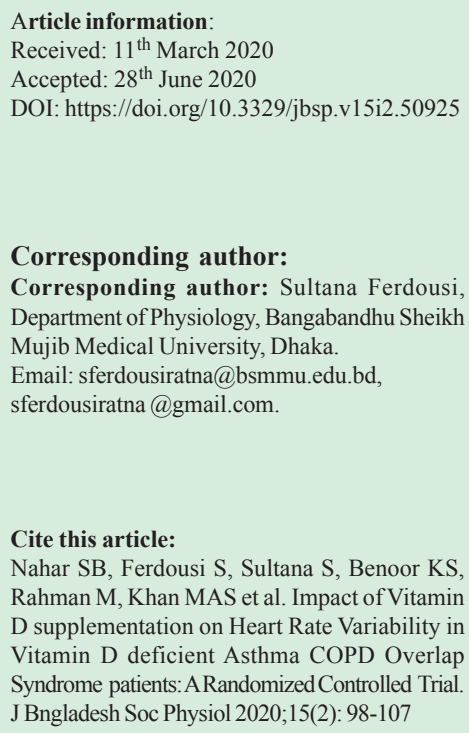

This article is open access licensed under CC BY NC SA which allows readers copy, distribute, display, and perform the work and make derivative works based on it only for noncommercial purposes.

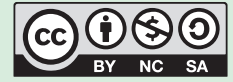

\section{Impact of Vitamin D supplementation on Heart Rate Variability in Vitamin D deficient Asthma COPD Overlap Syndrome patients: A Randomized Controlled Trial}

\author{
Salsa Bill Nahar ${ }^{1}$, Sultana Ferdousi ${ }^{1}$,Shamima \\ Sultana ${ }^{1}$ Kazi Saifuddin Bennoor ${ }^{2}$,Mustafijur Rahman ${ }^{2}$, \\ Mohammad Abdus Shakur Khan², Samia Hassan', \\ Maksuda Binte Mahmood ${ }^{1}$, Sharkia Khanam Rosy ${ }^{1}$, \\ Nazneen Sultana ${ }^{1}$, Sheikh Manna Yasmin ${ }^{1}$ \\ 1. Department of Physiology, Bangabandhu Sheikh Mujib Medical University, \\ Dhaka \\ 2. Department of Respiratory Medicine, National Asthma Center, National \\ Institute of the Diseases of Chest and Hospital, Dhaka.
}

\section{Abstract}

Background:Vitamin $\mathrm{D}_{3}$ deficiency is common in Asthma COPD overlap syndrome (ACO) and administration of vitamin $\mathrm{D}_{3}$ increased heart rate variability in healthy subjects. Objective: This randomized clinical trial aimed to investigate the therapeutic effect of vitamin $\mathrm{D}_{3}$ administration on time domain measures of heart rate variability in 51 male vitamin $\mathrm{D}_{3}(<30$ $10 \mathrm{ng} / \mathrm{ml}$ ) deficient ACO patients. Methods: Patients were given either vitaminD $\mathrm{D}_{3}$ capsule or placebo per week orally for 3 months and serum vitamin $\mathrm{D}_{3}$ level and time domain parameters of heart rate variability were assessed before and after the intervention. For statistical analysis, independent and paired sample t test was used. Results: Before intervention, vitamin $\mathrm{D}_{3}$ level and time domain parameters of heart rate variability were similar in all patients but these outcome measures significantly increased in vitamin $\mathrm{D}_{3}$ treated but not in placebo treated patients after 3 months. Conclusion:In conclusion, vitaminD $\mathrm{D}_{3}$ therapy is effective to improve heart rate variability in vitamin $\mathrm{D}_{3}$ deficient Asthma COPD overlap syndrome.

Key words: Vitamin $\mathrm{D}_{3}, \mathrm{ACO}, \mathrm{HRV}$ 
Introduction

ccording to Global Initiative for chronic
Obstructive Lung Disease (GOLD) and
Global Initiative for Asthma (GINA)(2017) the presence of features of both asthma and chronic obstructive pulmonary disease (COPD) in overlapping manner leads to a new disease entity as Asthma-COPD overlap (ACO). ${ }^{1}$ An epidemiological report showed prevalence rate of ACO between $15-55 \%$ and $11.6 \%$ in Bangladesh. ${ }^{1-2}$

The increased prevalence of vitamin D deficiency in the general population has been well recognized as a significant risk factor of different diseases. $^{3-4}$

Serum level of 25-hydroxyvitamin D less than $20 \mathrm{ng} / \mathrm{ml}$ is categorized as deficiency and 21-29 $\mathrm{ng} / \mathrm{ml}$ as insufficiency by endocrine society of USA. But vitamin D council recommended serum level of 25-hydroxyvitamin D less than $30 \mathrm{ng} / \mathrm{ml}$ as deficiency and 31-39 $\mathrm{ng} / \mathrm{ml}$ as insufficiency. ${ }^{5}$

High prevalence of vitamin D deficiency, has been reported in ACO patients and its level was found even lower than 11 asthma patients. It was correlated with disease severity in ACO patients. ${ }^{6}$

Heart rate variability (HRV) is an index of normal rhythmic variation of heart rate caused by different physiological factors. ${ }^{7}$ It represents the variation of beat to beat RR interval over a period of time and it can measure sympathetic and parasympathetic resting tone as well as the interplay of sympathetic and parasympathetic activity at any instant. ${ }^{8}$ Being a non stationary signal HRV can predict the upcoming danger of impending cardiac disease. ${ }^{7}$ As the balance between sympathetic and parasympathetic activity controls heart rate,sympathetic hyper and parasympathetic hypo-activity causes cardio acceleration or vice versa. The significant relationship between cardiac autonomic activity and cardiovascular mortality including sudden death is well recognized. ${ }^{8-9}$

Large number of studies highlighted the significant role of HRV to assess cardiac health. ${ }^{10-14}$ Reduced HRV is well known for its predicting power for adverse cardiovascular event and cardiac mortality risk specially after myocardial infarction. ${ }^{15-17}$ Reduced HRV has been used as a marker to identify early cardiac autonomic impairment. ${ }^{18}$

Previous studies demonstrated the relationship between vitamin $\mathrm{D}_{3}$ deficiency and reduced HRV causing increased incidence of cardiovascular disease. 19-21 Very recently, Nalbant et al. ${ }^{22}$ investigated the relationship between vitamin $\mathrm{D}$ and time domain parameters of HRV and found mean RR, mean HR, SDNN, SDANN, SDNNI, RMSDD, and PNN50 did not differ significantly between vitamin $\mathrm{D}$ deficient and non deficient groups whereas Tak et al. ${ }^{21}$ found significantly lower SDNN in vitamin D deficient group than non deficient group as well as showed positive relation with vitamin $\mathrm{D}$ level.

Only two previous studies reported the effect of vitamin $\mathrm{D}_{3}$ administration on $\mathrm{HRV}^{19,23}$. Mann et al. ${ }^{23}$ showed improvement of sympathovagal balance after adminstration of vitamin $\mathrm{D}_{3}$. In contrast, no alteration of cardiac autonomic tone was reported after vitamin $\mathrm{D}$ administration in vitamin $\mathrm{D}$ deficient subjects by Burt et al. ${ }^{19}$ Results of these two studies are controversial regarding the effect of vitamin $\mathrm{D}$ on cardiac autonomic tone.

However, vitamin $\mathrm{D}_{3}$ appears to be a simple, cost effective treatment to reduce cardiovascular disease associated risk by improving function of autonomic nerve function in both healthy and chronic disease population worldwide. ${ }^{24}$ But the volume of information regarding the effect of vitamin $\mathrm{D}_{3}$ administration in ACO patients is not

Volume 15 No. 2 December 2020: 98-107 
enough for reaching any final conclusion. Moreover, with the best of our knowledge no study have been conducted to observe the effects of this fat soluble vitamin on HRV in vitamin $\mathrm{D}_{3}$ deficient, stable patients with ACO.

Therefore, the present study has been designed to evaluate the impact of vitamin $\mathrm{D}_{3}$ administration on heart rate variability analysis by time domain method in $\mathrm{D}_{3}$ deficient, stable patients with ACO.

\section{Method}

Study design

This randomized double blind placebo controlled trial with parallel allocation design was conducted in the Department of Physiology, Bangabandhu Sheikh Mujib Medical University (BSMMU), Shahbag, Dhaka and Department of Respiratory Medicine, National Institute of the Disease of Chest and Hospital (NIDCH), Mohakhali, Dhaka from September 2017 to August 2018.

\section{Study population}

Consecutive sampling was followed to select the ACO patients ((diagnosed by applying the "tick box" approach) recommended by the joint committee of ${ }^{1}$ GOLD \& GINA by physicians of NIDCH, Mohakhali, Dhaka. Total 51 male stable patients of ACO with $>1$ years of disease duration with age $40-80$ years ${ }^{18}$ and vitamin D deficient(serum 25-hydro-xycholecalciferol, $25(\mathrm{OH}) \mathrm{D}_{3}$ level $<30 \mathrm{ng} / \mathrm{ml}$ but $>10 \mathrm{ng}^{4}$ with normal serum $\mathrm{Ca}^{+}(8.7-10.2 \mathrm{mg} / \mathrm{dl})$, inorganic phosphate (2.5-4.3 mg/dl) level were enrolled to this study. ${ }^{25} \mathrm{~A}$ CONSORT flow diagram of enrollment and progress through intervention period is shown in figure 1. Patients with diabetes and hypertension were included in this study as it was difficult to find ACO patients in the defined age group without these two diseases but its number was adjusted in two comparison groups. Any patient with any acute condition, unstable patients with ACO (patients with exacerbation and medication changes in the past 30 days), with acute exacerbation of any pulmonary,cardiac diseases, history of endocrine,neurological disorder, Rheumatoid arthritis, renal diseases, SLE, IBS or receiving any drugs that can affect autonomic nervous system or vitamin D metabolism were excluded from the study.

\section{Sampling}

Sample size was calculated by a statistical equation based on effect size published in a similar study. ${ }^{26-27}$ Consecutive sampling was followed for preliminary selection of the ACO patients from the outpatient department of NIDCH.

\section{Randomization}

After screening of serum vitamin $\mathrm{D}_{3}$, vitamin $\mathrm{D}$ deficient ACO patients were finally selected by principal investigator. All patients were randomly assigned into vitamin $D$ therapy group $(n=26)$ or placebo treated group $(n=25)$ using a computer generated random table.Any patient had equal chance to belong any group. Their identification has been hidden and a code was provided to each patient.Randomization and blinding was done by a third party, not member of the research team. Both the researcher and the data recorder as well as patients were unaware about the grouping of the patients. Before the data analysis, grouping of the patient was disclosed.

\section{Study Interventions}

Intervention was done by administering vitamin D capsule or placebo to patients. Patients allocated for vitamin $\mathrm{D}_{3}$ therapy received 80,000 IU of vitamin $\mathrm{D}_{3}$ (2 capsules orally) per week for 3 months, whereas the patients of placebo group received placebo ( 2 capsules orally) for similar duration.Vitamin D capsules were manufactured and supplied by BeximcoPharma, Bangladesh. The vitamin D capsules were composed of cholecalciferol (40,000 IU), microcrystalline 
cellulose (58.1 gm), butylatedhydroxy toluene $(0.2 \mathrm{mg})$, magnesium stearate $(3 \mathrm{mg})$, gelatin capsule shell (1 mg). Placebo was composed of similar substances except cholecalciferol and it was look alike to vitamin D capsule and was prepared and supplied by the same pharmaceutical company. All the selected ACO patients were allowed to continue standard therapeutic treatment as prescribed by the physician for these three months. Before beginning intervention the schedule of the therapy and possible side effect (diarrhoea) was explained meticulously and advised to contact researcher by telephone if there was any such complain. In addition, they were advised to bring along the empty blisters of capsule foil when they would report for follow up to ensure the consumption of the drug. During the intervention period, the patient was regularly monitored and encouraged to be the part of this study by maintaining regular communication through telephonic calls several times a week. A good rapport was built up to take time to time follow-up over telephone and visiting patient's place.

\section{Study Outcomes}

The primary target of the study was to observe the effect of vitamin $\mathrm{D}_{3}$ therapy on $\mathrm{HRV}$ in $\mathrm{ACO}$ patients after 3 months. This was achieved by observing the changes in serum vitamin D concentration and in several time domain measures of HRV(Mean heart rate, Mean RR,SDRR,CV RR, SDSD, RMSSD\& pRR50\%)from baseline to endpoint after 3 months intervention with either vitamin $\mathrm{D}_{3}$ or placebo.

\section{Data collection}

After taking informed consent, anthropometric measurement and socio demographic data of all patients were recorded in a data schedule. Then $5 \mathrm{ml}$ of venous following blood were drawn for biochemical estimation of serum $25(\mathrm{OH}) \mathrm{D}$, serum calcium and serum inorganic phosphate. ${ }^{28} \mathrm{HRV}$ data were recorded by a data acquisition device, powerlab 8/35, AD instruments, Australia after a prescribed preparation in the previous night. All patients were advised to finish their meal by $9 \mathrm{pm}$ and to have sound sleep avoiding anxiety tension and not to use any sedative or any drug affecting CNS. In the morning, after a light breakfast but without coffee or tea and also refrain from smoking, they were asked to report in the autonomic lab in the department of Physiology, BSMMU.A 5 minute ECG recording of the patient in supine position after giving 10 minutes rest in a comfortable room temperature about 25 degree celsius and noise free laboratory environment was done. The lab chart software of the power lab automatically generated the time domain measures of HRV from the recorded RR interval of the short term ECG acquired.HRV measures and serum vitamin $\mathrm{D}_{3}$ level of all patients were recorded at baseline and then after 3 months of intervention in both group. Serum 25(OH)D level of all these patients were measured by chemiluminescentmicroparticle immunoassay (CMA) method by autoanalyzer ARCHITECT Plus ci4100. Serum calcium and inorganic phosphate were assessed by coloremetricand microcoloremetric method respectively using reagents of Siemens Clinical Laboratory. ${ }^{28-29}$ All these biochemical assessment was done in the laboratory of the Biochemistry and Molecular Biology of BSMMU.

\section{Statistical Analysis}

Data were expressed as mean \pm SD.For statistical analysis, paired sample $t$ test and independent sample $t$ test was done for group comparison as applicable.Data was analyzed by SPSS version 16.In the interpretation of result, $\mathrm{p}<0.05$ was taken as significant.

Volume 15 No. 2 December 2020: 98-107 


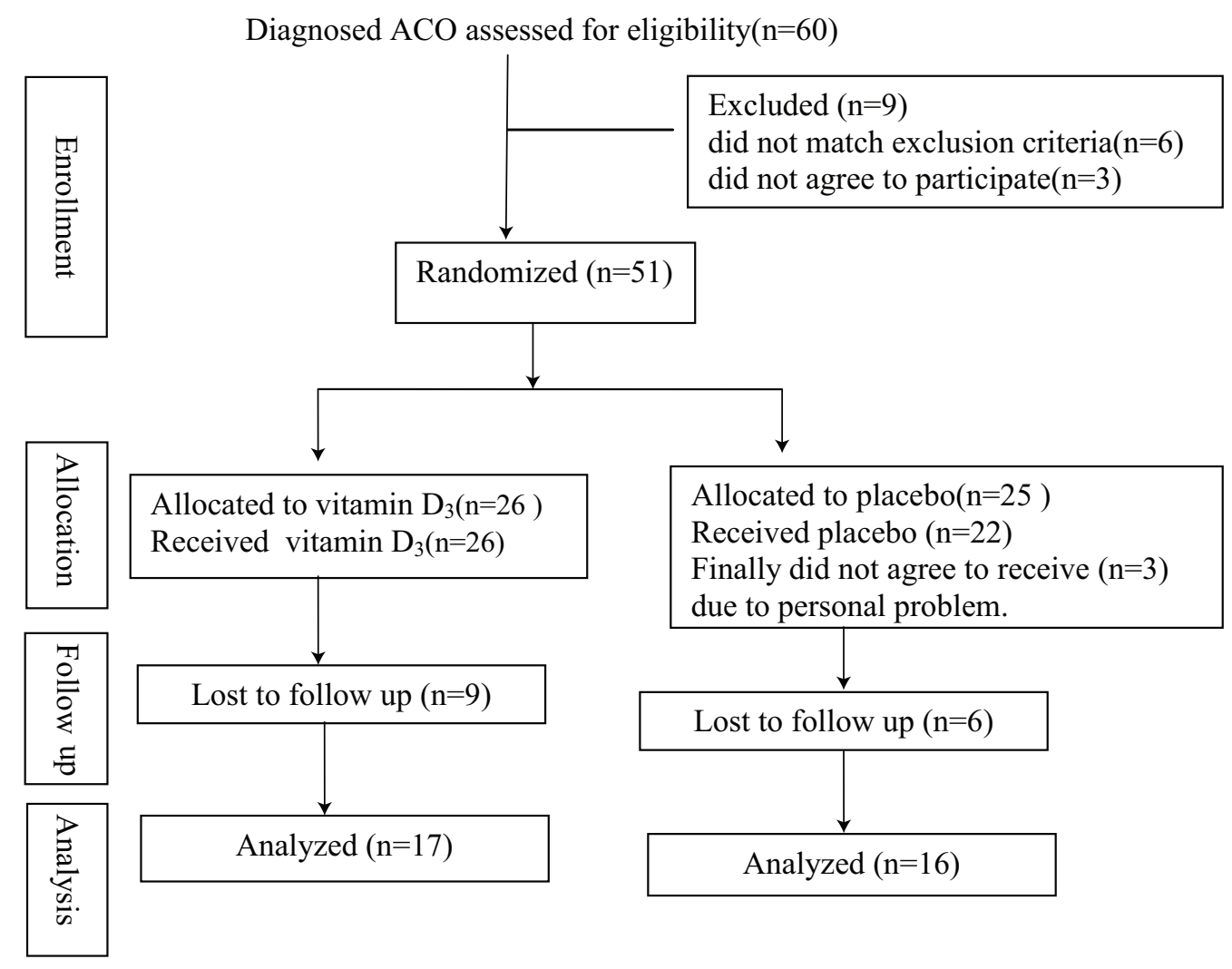

Figure 1: Progress of trial participants through phases of parallel groups randomized.

Results

Study Participants

In this study, $51 \mathrm{ACO}$ patients were initially enrolled after screening exclusion criteria. Twenty six (26) patients were randomly allocated to vitamin $\mathrm{D}$ group and all these patients agreed to receive Vitamin $\mathrm{D}_{3}$ capsule orally but 9 patients were lost during intervention period and 17 patients completed the intervention with vitamin $\mathrm{D}_{3}$ for 90 days (3 months). In placebo group, 25 patients were allocated by randomization but 3 patients later did not agree to receive placebo and 6 patients did not appear at the end of 3 months follow up. Finally data of 17 patients of vitamin $\mathrm{D}$ group and 16 patients of placebo group were used in analysis.
In the present study, the baseline characteristics of the placebo and vitamin $\mathrm{D}$ group before intervention were similar (Table I). The number of hypertensive or Diabetes mellitus patients individually and combined hypertensive and Diabetes mellitus patients as well as frequency of anti hypertensive and anti diabetes drug user were not significantly different in these two groups of patients.(Table II)

Time domain measures of HRV

All time domain measures of HRV also did not differ significantly between placebo and vitamin D groups at baseline(Table III). All the values of time domain parameters significantly $(\mathrm{p}<0.05)$ increased but heart rate decreased after 90 days 
of vitamin D administration except in pRR $50 \%$. But in the placebo group no significant change in time domain parameters were observed after 90 days follow up data (Table IV). In addition, SDRR and CVRR were found significantly $(p<0.05)$ higher in ACO patients after vitamin D administration when compared to these values in placebo group after 90 days follow up (Table IV).

\section{SerumVitamin D}

The vitamin $\mathrm{D}_{3}$ level increased significantly $(\mathrm{p}<0.05)$ in vitamin D treated ACO patients after 90 days of vitamin $\mathrm{D}$ administration but no significant follow up change in vitamin $\mathrm{D}$ level was observed in placebo group ( $\mathrm{p}>0.05$ ) (Table IV).

Table I:Age, BMI, Waist-hip ratio, MUAC, resting pulse rate, SBP, DBP and vitamin D in vitamin D deficient ACO patients for placebo and vitamin D group at baseline $(n=33)$

\begin{tabular}{lcc}
\hline Parameters & Placebo $(\mathrm{n}=16)$ & Vitamin D $(\mathrm{n}=17)$ \\
\hline Age $($ years $)$ & $58.6 \pm 11.5$ & $59.9 \pm 6.3$ \\
& $(40-80)$ & $(48-68)$ \\
BMI $\left(\mathrm{Kg} / \mathrm{m}^{2}\right)$ & $22.6 \pm 4.0$ & $22.2 \pm 2.3$ \\
Waist-hip ratio & $(15.3-31.2)$ & $(19.2-26.4)$ \\
& $0.9 \pm 3.5$ & $0.9 \pm 0.5$ \\
MUAC $(\mathrm{cm})$ & $(0.8-1.0)$ & $(0.8-0.9)$ \\
& $26.6 \pm 3.5$ & $26.7 \pm 2.1$ \\
Vitamin ${ }_{3}(\mathrm{ng} / \mathrm{ml})$ & $(20-34)$ & $(23-30)$ \\
& $20.0 \pm 3.5$ & $19.6 \pm 4.4$ \\
Pulse rate $(\mathrm{beats} / \mathrm{min})$ & $(15-27.2)$ & $(13.4-28.5)$ \\
& $73 \pm 4.9$ & $75.1 \pm 4.2$ \\
SBP $(\mathrm{mmHg})$ & $(60-80)$ & $(63-80)$ \\
& $120.6 \pm 8.0$ & $117.6 \pm 8.2$ \\
DBP $(\mathrm{mmHg})$ & $(110-140)$ & $(100-130)$ \\
& $78.1 \pm 3.8$ & $77.0 \pm 6.8$ \\
\end{tabular}

Data were expressed as Mean \pm SD. Values in parentheses indicate ranges; Statistical analysis was done by Independent sample t-test.BMI- body mass index; MUAC- mid upper arm circumference; SBP- Systolic Blood Pressure; DBP-Diastolic Blood Pressure.

Table II: Frequency distribution of comorbidity and use of drugs in two groups $(\mathrm{n}=33)$

\begin{tabular}{lcc}
\hline Parameters & $\begin{array}{c}\text { Placebo(n }=16) \\
\text { no. }(\%)\end{array}$ & Vitamin D(n=17) \\
\hline HYTN & $2(15)$ & $4(23)$ \\
DM & $6(35)$ & $5(30)$ \\
HYTN\& DM & $2(10)$ & $3(15)$ \\
Anti HYTN & $3(20)$ & $5(30)$ \\
Anti DM & - & $1(7)$ \\
\hline
\end{tabular}

Data are presented in number and percent.Chi square test was used for analysis. HYTN-Hypertension;DMDiabetes mellitus 
Table III:Time domain measures of HRV in vitamin D deficient ACO patients for placebo and vitamin $\mathrm{D}$ group at baseline $(\mathrm{n}=33)$

\begin{tabular}{lcc}
\hline Parameters & Placebo $(\mathrm{n}=16)$ & Vitamin $\mathrm{D}(\mathrm{n}=17)$ \\
\hline Mean heart rate (beats/min) & $76.5 \pm 2.8$ & $78 \pm 1.1$ \\
& $(61.2-100.7)$ & $(52.8-108.2)$ \\
Mean R-R interval $(\mathrm{ms})$ & $801.0 \pm 28.7$ & $776.2 \pm 147.4$ \\
& $(596.6-980.6)$ & $(556-1137)$ \\
SDRR(ms) & $21.3 \pm 1.1$ & $22.5 \pm 8.1$ \\
& $(14.6-29.7)$ & $(14.3-43.2)$ \\
CVRR & $0.02 \pm 0.00$ & $0.02 \pm 0.01$ \\
& $(0.015-0.04)$ & $(0.015-0.044)$ \\
SDSD $(\mathrm{ms})$ & $17.5 \pm 1.9$ & $16.1 \pm 10.8$ \\
& $(8.3-35.2)$ & $(6.4-44.2)$ \\
RMSSD(ms) & $17.5 \pm 1.9$ & $16.1 \pm 10.7$ \\
& $(8.3-35.2)$ & $(6.4-44.1)$ \\
pRR50\% & $1.4 \pm 0.6$ & $2.5 \pm 7.2$ \\
& $(0-9.2)$ & $(0-29.8)$ \\
\hline
\end{tabular}

Data were expressed as Mean $\pm \mathrm{SD}$. Values in parentheses indicate ranges.Statistical analyses were done by Independent sample t-test.SDRR-Standard deviation of all RR interval; CVRR-Coefficient of variance of RR interval; SDSDStandard deviation of successive RR interval differences between adjacent RR intervals; RMSSD-Square root of mean of squared differences of successive RR interval; pRR50\%-Proportionof RR interval with duration $>50 \mathrm{~ms}$;

Table IV: Pre and post intervention values of time domain measures in vitamin D deficient ACO patients $(\mathrm{n}=33)$

\begin{tabular}{|c|c|c|c|c|}
\hline \multirow[t]{2}{*}{ Parameters } & \multicolumn{2}{|c|}{ Placebo $(n=16)$} & \multicolumn{2}{|c|}{ Vitamin D $(n=17)$} \\
\hline & Pre & Post & Pre & Post \\
\hline Vitamin $\mathrm{D}_{3}$ & $20.0 \pm 3.5$ & $21.9 \pm 5.6$ & $19.6 \pm 4.4$ & $93.0 \pm 24.3^{*}$ \\
\hline$(\mathrm{ng} / \mathrm{ml})$ & $(15-27.2)$ & $(12-35)$ & $(13.4-28.5)$ & $(34.8-151)$ \\
\hline $\begin{array}{l}\text { Mean heart rate } \\
\text { (beats/min) }\end{array}$ & $\begin{array}{c}76.5 \pm 11.4 \\
(61.2-100.7)\end{array}$ & $\begin{array}{c}71.9 \pm 12.3 \\
(50.7-97.8)\end{array}$ & $\begin{array}{c}78 \pm 15.2 \\
(52.8-108.2)\end{array}$ & $\begin{array}{l}71.4 \pm 10.3^{*} \\
(54.4-87.3)\end{array}$ \\
\hline $\begin{array}{l}\text { Mean R-R interval } \\
(\mathrm{ms})\end{array}$ & $\begin{array}{c}801.1 \pm 114.8 \\
(596.6-980.6)\end{array}$ & $\begin{array}{l}869.2 \pm 148.4 \\
(613.7-1182)\end{array}$ & $\begin{array}{c}776.2 \pm 149.2 \\
(556-1137)\end{array}$ & $\begin{array}{c}836.5 \pm 126.1 * \\
(664.8-1103)\end{array}$ \\
\hline SDRR (ms) & $\begin{array}{c}21.3 \pm 4.4 \\
(14.6-29.7)\end{array}$ & $\begin{array}{c}23.3 \pm 7.6 \\
(13.6-40.7)\end{array}$ & $\begin{array}{c}22.5 \pm 8.1 \\
(14.3-43.2)\end{array}$ & $\begin{array}{l}31.2 \pm 11.4^{* \#} \\
(14.4-57.6)\end{array}$ \\
\hline CVRR & $\begin{array}{c}0.02 \pm 0.01 \\
(0.015-0.04)\end{array}$ & $\begin{array}{c}0.02 \pm 0.02 \\
(0.015-0.046)\end{array}$ & $\begin{array}{c}0.02 \pm 0.02 \\
(0.015-0.044)\end{array}$ & $\begin{array}{c}0.038 \pm 0.01^{\text {*\# }} \\
(0.022-0.086)\end{array}$ \\
\hline SDSD (ms) & $\begin{array}{c}17.5 \pm 7.6 \\
(8.3-35.2)\end{array}$ & $\begin{array}{c}20.9 \pm 12.00 \\
(5.8-46.2)\end{array}$ & $\begin{array}{l}16.1 \pm 10.8 \\
(6.4-44.2)\end{array}$ & $\begin{array}{c}25.3 \pm 14.5^{*} \\
(9.1-53.7)\end{array}$ \\
\hline RMSSD (ms) & $\begin{array}{c}17.5 \pm 7.8 \\
(8.3-35.2)\end{array}$ & $\begin{array}{c}20.8 \pm 12.00 \\
(5.7-46.3)\end{array}$ & $\begin{array}{l}16.1 \pm 10.7 \\
(6.4-44.1)\end{array}$ & $\begin{array}{l}25.4 \pm 14.8^{*} \\
(0.08-53.7)\end{array}$ \\
\hline pRR50\% & $\begin{array}{l}1.5 \pm 2.4 \\
(0-9.2)\end{array}$ & $\begin{array}{l}5.1 \pm 6.6 \\
(0-17.9)\end{array}$ & $\begin{array}{l}2.5 \pm 7.3 \\
(0-29.8)\end{array}$ & $\begin{array}{l}4.7 \pm 8.7 \\
(0-29.5)\end{array}$ \\
\hline
\end{tabular}

Data were expressed as Mean $\pm \mathrm{SD}$. Values in parentheses indicate ranges. Statistical analyses were done by Independent sample t-test. SDRR-Standard deviation of all RR interval; CVRR-Coefficient of variance of RR interval; SDSD- Standard deviation of successive RR interval differences between adjacent RR intervals; RMSSDSquare root of mean of squared differences of successive RR interval; pRR50\%-Proportion of RR interval with duration $>50 \mathrm{~ms} ;(* \mathrm{p}<0.05=$ pre vs post; $\# \mathrm{p}<0.05=$ post vs post $)$

Volume 15 No. 2 December 2020: 98-107 
Discussion

In this study, mean HR decreased and mean RR interval, SDRR, CVRR, SDSD, RMSSD and pRR $50 \%$ increased in ACO patients after vitamin $\mathrm{D}_{3}$ administration. All these changes were significant except the change in pRR $50 \%$. Similar changes in placebo group were not significant in any time domain parameters of HRV. Moreover, when comparison was done between the post intervention values of time domain parameters in vitamin $\mathrm{D}_{3}$ treated and placebo treated $\mathrm{ACO}$ patients, SDRR and CVRR were found significantly higher in vitamin $\mathrm{D}$ group compared to the post follow up values of placebo group.

A previous study in Turkey, did not find significant difference in all these time domain parameters when compared between vitamin $\mathrm{D}_{3}$ deficient patients with low cardiovascular risk and healthy subjects with normal vitamin $\mathrm{D}_{3}$ level. ${ }^{22}$ In a similar study, Tak et al. ${ }^{21}$ found significant positive association between SDNN and serum 25 hydroxy vitamin $\mathrm{D}_{3}$ levels which was sustained even after adjusting for age, sex and seasons of vitamin $\mathrm{D}_{3}$ measurement by regression analysis. But they did not find significant relation of RMSSD with vitamin $\mathrm{D}_{3}$ level. Moreover, they did not find any significant difference in SDNN and RMSSD values between vitamin $\mathrm{D}_{3}$ deficient and non deficient group of healthy people. ${ }^{21}$

The changes observed in these time domain parameters after 3 months vitamin $D_{3}$ administration suggests improvement of cardiac parasympathetic tone in $\mathrm{D}_{3}$ deficient $\mathrm{ACO}$ patients. $^{8}$

The data of the present study indicate significant improvement in cardiac parasympathetic function in vitamin $\mathrm{D}_{3}$ deficient $\mathrm{ACO}$ patients after 3 months administration of vitamin $\mathrm{D}_{3}$ which is strongly supported by significantly higher value in SDRR and CVRR in vitamin $\mathrm{D}_{3}$ supplemented patients than non supplemented ACO patients after 3 months. The lack of significant changes in most of the time domain measures of HRV in placebo treated patients after 3 months demonstrate no effect of placebo on HRV in vitamin D deficient ACO patients. It is important to note that no patients remained $\mathrm{D}$ deficient after 3 months of vitamin $\mathrm{D}_{3}$ therapy whereas most of the placebo treated remained $\mathrm{D}$ deficient after 3 months of intervention. Therefore it is evident from our data that 3 months vitamin $\mathrm{D}_{3}$ therapy in ACO patients might be effective to increase cardiac parasympathetic activity in ACO patients by increasing theirvitamin $\mathrm{D}_{3}$ level.

Very little information is available to explain the relationship between vitamin $\mathrm{D}$ and cardiac parasympathetic nerve function in ACO patients. Two previous studies observed the effect of vitamin $\mathrm{D}_{3}$ administration on vitamin $\mathrm{D}_{3}$ deficient healthy subject. Research evidence identified the presence of vitamin $\mathrm{D}$ receptor (VDR) rich autonomic neurons and vitamin $\mathrm{D}_{3}$ can cross the blood brain barrier to bind to this VDR in $\mathrm{CNS}^{30-31}$ But the exact connection between VDR activity on autonomic neurons and modulation of cardiac autonomic tone has not yet been known. One experimental study on spontaneously hypertensive rats (SHR) demonstrated the mechanism how vitamin $\mathrm{D}_{3}$ supplementation restore impaired effect of acetylcholine on vascular tone. In SHR, this effect of acetylcholine is impaired. Administration of vitamin $\mathrm{D}_{3}$ was found to normalize the $\mathrm{Ca}^{+}$ dependent $\mathrm{K}^{+}$channels in SHR and brings the relaxation and hyper polarization effect of acetylcholine to normal. Thus vitamin $\mathrm{D}_{3}$ supplementation brings these responses to levels similar to those of normotensive rats. ${ }^{32}$

However, any of these above mentioned mechanisms are not exactly applicable to explain our findings in some improvement of cardiac autonomic tone after 90 days of administration of vitamin $\mathrm{D}_{3}$, by increasing parasympathetic function in vitamin $\mathrm{D}_{3}$ deficient $\mathrm{ACO}$ patients in the present study.

Volume 15 No. 2 December 2020: 98-107 


\section{Conclusion}

From the result of this study, it may be concluded that vitamin $\mathrm{D}_{3}$ administration may improve autonomic function by increasing the parasympathetic activity in ACO patients who were deficient of this vitamin.

Ethical issue- The ethical aspects of the study following the Helsinki declaration involving human and technical aspects of the study was approved by the Institutional Review Board of BSMMU(No.BSMMU/2018/478 Date 14/01/ 2018) and also allowed by the authority of NIDCH for data collection. Every precaution was taken to maintain the confidentiality of the patients and informed consent were taken.

Registration of clinical trial-This Clinical Trial registration was done with Clinical trials.gov PRS system ID NCT03773809 where full protocol can be accessed.

Conflict of interest -Authors declare no conflict of interest

\section{Acknowledgement}

This study was supported by an unrestricted educational grant from Beximco Pharmaceuticals Ltd. Bangladesh. The funding body had no role in design, data collection, analysis, interpretation and manuscript preparation.

\section{References}

1. Global Initiative for Asthma and Global Initiative for Chronic Obstructive Lung Disease. Diagnosis of Diseases of Chronic Airflow Limitation: Asthma, COPD and Asthma-COPD Overlap (ACO) [Internet]. A joint project of GINA and GOLD [updated April 2017; Cited 2017 Nov12].Availablefrom: CalidadSNS/ pdf/GOLD_ACOS_2017.pdf

2. Habib GMM, Nahar K, Habib F. Prevalence of Asthma and COPD Overlapping Syndrome (ACOS) in a busy primary care setting of Bangladesh. 1st IPCRG South Asian Scientific Conference: 2017, 3-5 Agaust; Colombo. Sri Lanka

3. Dobnig H, Pilz S, Scharnagl H, Renner W, Seelhorst U, Wellnitz B, Kinkeldei J, Boehm BO, Weihrauch G, Maerz W. Independent association of low serum 25- hydroxyvitamin D and 1, 25-dihydroxyvitamin D levels with all-cause and cardiovascular mortality. Arch Intern Med 2008;168(12):1340-49.

4. Holick MF, Binkley NC, Bischoff-Ferrari HA, Gordon CM, Hanley DA, Heaney RP, Murad MH, Weaver CM. Evaluation, Treatment, and prevention of vitamin D deficiency: an Endocrine Society Clinical Practice Guideline. J Clin Endocrinol Metab. 2011;96(7):191130

5. Vitamin D council. I tested my vitamin D level. What do my result mean? 2017 [Internet]. [Cited 2017 Oct 25]. Available from: https://www.vitamindcouncil.org/ i-tested-my-vitamin-d-levelwhat-do-result-mean/

6. Odler B, Ivancso I, Somogyi V, Benke K, Tamasi L, Gabriella G, Szalay B, Muller V.Vitamin D deficiency is associated with impaired disease control in asthma COPD overlap syndrome patients. Int J Chronic Obstruct Pulm Dis. 2015;(10):2017-25.

7. Acharya UR, Joseph KP, Kannathal N, Lim CM, Suri JS. Heart rate variability: a review. Med Biol Eng Comput 2006;44(12): 1031-51

8. Malik M, Task Force of the European Society of Cardiology and the North American Society of Pacing and Electrophysiology. Heart rate variability: standards of measurement, physiological interpretation and clinical use. Eur Heart J. 1996;17:351-81.

9. Schwartz PJ, Priori SG. Sympathetic nervous system and cardiac arrythmias. In: Zipes DP, Jalife J (eds) Cardiacelectrophysiology. From cell to bedside.Philadelphia : W.B. Saunders;1990. pp 33043.

10. Berger RD,Akselrod S,Gordon D,Cohen RJ.An efficient algorithm for spectral analysis of heart rate variability.IEEE Trans Biomed Eng. 1986; 33:900-4

11. Akselrod S, Gordon D, Ubel FA, Shannon DC, BargerMA, Cohen RJ. Power spectrum analysis of heart rate fluctuation.Science. 1981;213:220-2

12. Kamath MV, Fallen EL. Power spectral analysis of heart rate variability: a noninvasive signature of cardiac autonomic function. Crit Rev Biomed Eng. 1993; 21(3):245-311

13. Kamath MV, Fallen EL Correction of the heart rate vaiability signal for ectopics and missing beats. In: Malik M,Camm AJ (eds) Heart rate variability. Futur:, Armonk; 1995. pp75-85

14. Pagani M, Lombardi F, Guzzetti S et al. Power spectral analysis of heart rate and arterial pressure variabilities as a marker of sympatho-vagal interaction in man and conscious dog. Circ Res. 1986; 59:178-93 
15. Bigger JT, Fleiss JL, Steinman RC, Rolnitzky LM, Kleiger RE, RottmanJN.Frequency domain measures of heart period variability and mortality after myocardial infarction. Circulation.1992;85 (1):16471. doi:10.1161/01.CIR.85.1.164.PMID 1728446

16. La Rovere MT, Bigger JT, Jr, Marcus FI, Mortara A, Schwartz PJ. Baroreflex sensitivity and heart-rate variability in the prediction of total cardiac mortality after myocardial infarction. ATRAMI (Autonomic Tone and Reflexes After Myocardial Infarction) Investigators. Lancet. 1998;351:478-84.

17. Tsuji H, Larson MG, Venditti FJ, Jr, Manders ES, Evans JC, Feldman CL, Levy D. Impact of reduced heart rate variability on risk for cardiac events. The Framingham Heart Study. Circulation. 1996;94:2850-55.

18. Ziegler D, Zentai CP, Perz S, Rathmann W, Haastert B, Doring A, Meisinger C. Prediction of mortality using measures of cardiac autonomic dysfunction in the diabetic and nondiabetic population: the MONICA/ KORA Augsburg Cohort Study. Diabetes Care 2008; 31:556-61. [PubMed: 18086873]

19. Burt MG, Mangelsdorf BL, Stranks SN, Mangoni AA. Relationship between vitamin D status and autonomic nervous system activity. Nutrients. 2016;8(9): 565

20. Deo R, Katz R, Shlipak MG, Sotoodehnia N, Psaty BM, Sarnak MJ, Fried LF, Chonchol M, de Boer IH, Enquobahrie D, Siscovick D. Vitamin D, parathyroid hormone and sudden cardiac death: results from the cardiovascular health study. Hypertension. 2011; 58(6): 1021-28

21. Tak YJ, Lee JG, Kim YJ, Lee SY and Cho BM. 25Hydroxyvitamin $\mathrm{D}$ and its relationship with autonomic dysfunction using time- and frequency-domain parameters of heart rate variability in Korean populations: A Cross-Sectional Study. Nutrient. 2014;10(6): 4373-88.

22. Nalbant A, Vatan MB, Varým P, Varým C, Varým T, Tamer A. Does Vitamin D deficiency effect heart rate variability in low cardiovascular risk population? Maced J Med Sci. 2017;5(2):197-200
23. Mann MC, Exner DV, Hemmelgrar BR, Sola DY, Turin TC, Ellis L, Ahmed SB. Vitamin D supplementation is associated with improved modulation of cardiac autonomic tone in healthy humans. Int J Cardiol. 2014;172(2):506-8

24. Mann MC, Hollenberg MD, Hanley DA, Ahmed SB. Vitamin D, the autonomic nervous system and cardiovascular risk. Physiol Rep. 2015;3(4):1-5

25. Lomgo DL, Kasper DL, Jameson JL, Fauci AS, Hauser SL, Loscalzo J(Eds.). Harrison's Principles of Internal Medicine. $18^{\text {th }}$ ed. New York: The McGraw-Hill Companies; 2018. Appendix p. 3585-610

26. Kirkwood BR, Sterne JAC. Essential Medical Statistics. $2^{\text {nd }}$ ed. Bodmin (Cornwall): Blackwell; Chapter, calculation of required sample size; 2003.p. 425-40.

27. Kardelen F, Tezcan G, Akcurin G, Ertug H, Yesilipek A. Heart Rate Variability in Patients with Thalassemia Major. Pediatr Cardiol.2008;29:935-9.DOI:10.1007/ s00246-008-9240-1

28. Gran FC. A colorimetric method for the determination of calcium in blood serum.Actaphysiologica. 1960; 49(2-3):192-7.

29. Tausskey HH, Shorr E. a Microco-lorimetric method for the determination of inorganic phosphorus. J Biol Chem. 1952; 202(2):675-85

30. Garcion E, Wion-Barbot N, Montero-Menei CN, Berger F, Wion D. New clues about vitamin D functions in the nervous system. Trends EndocrinolMetab. 2002; 13(3):100-05

31.DeLuca GC, Kimball SM, Kolasinski J, Ramagopalan SV, and Ebers GC. Review: The role of vitamin D in nervous system health and disease. Neuropathol Appl Neurobiol. 2013;39: 458-84

32. Borges ACR, Feres T, Vianna LM, Paiva TB. Effect of cholecalciferol treatment on the relaxant responses of spontaneously hypertensive rat arteries to acetylcholine. Hypertension 1999; 34(4):897-901 